Portland State University

PDXScholar

$5-29-2019$

\title{
The Synthesis of Di-substituted DOTA Ligands for MRI Contrast Agents
}

Chau V. Nguyen

Portland State University

Follow this and additional works at: https://pdxscholar.library.pdx.edu/honorstheses

Let us know how access to this document benefits you.

\section{Recommended Citation}

Nguyen, Chau V., "The Synthesis of Di-substituted DOTA Ligands for MRI Contrast Agents" (2019).

University Honors Theses. Paper 754.

https://doi.org/10.15760/honors.771

This Thesis is brought to you for free and open access. It has been accepted for inclusion in University Honors Theses by an authorized administrator of PDXScholar. Please contact us if we can make this document more accessible: pdxscholar@pdx.edu. 


\title{
UNDERGRADUATE
}

HONOR THESIS

\section{The Synthesis of Di-substituted DOTA}

Ligands for MRI Contrast Agents.

\author{
Student: Chau Nguyen
}

Thesis Advisor: Dr. Mark Woods

Chemistry Department

University Honors

Portland State University 


\section{ABSTRACT}

The complex between the macrocyclic ligand DOTA and the metal gadolinium $\left(\mathrm{Gd}^{3+}\right)$ has been used as the contrast agent for the $\mathrm{MRI}_{1}$ weighed imaging. Mono substitution on the tetraaza ring of DOTA ligand results in the formation of the two distinct complexes that are regioisomers of each other and they have different contrast efficiency as well as stability. These regioisomers are only separated by HPLC. With two bulky substituents on the tetraaza ring, it is expected to increase the selectivity of what regioisomers will be formed for each di-substituting pattern since the conformation with the least steric hindrance will be favored most to maintain the stability of the ring structure. This will simplify the synthesis procedure by removing the separation of the different regioisomers. The contrast efficiency and stability of the complexes made from these new ligands will also need to be explored. Based on the special characteristics of the DOTA's tetraaza ring, three di-substitution patterns will be studied are 2,8-S,S, 2,9-S,S, and 2,5-S,S. This paper's goal is to report the synthesis progress of these three patterns. The synthesis includes four main stages: dibenzyl polypeptide chain, dibenzyl tetra amine chain, dibenzyl tetraaza cyclododecane, and dibenzyl DOTA. Cyclization in the third stage is crucial to control the di-substitution patterns. The identity of the product in each step was verified by using ${ }^{1} \mathrm{H}-\mathrm{NMR}$ and mass spectrometry. Pattern 2,9-S,S passed the first two stages and its dibenzyl tetraamine chain needs to be purified before entering the cyclization process. Pattern 2,8-S,S could not be built from the $\mathrm{N}$ terminal (after building the second peptide bonds, the intermediate product had solubility issues.) The first peptide bond for the pattern 2,5-S,S is still being built from the $\mathrm{N}$ terminal.

\section{INTRODUCTION}

\section{The use and limitation of DOTA in MRI imaging technique}

MRI imaging has been widely used for the diagnosing purposes in the medical fields because this technique does not require the use of radioactive isotopes and provides high spatial resolution ${ }^{[1]}$ [2] [3]. Many different scans and contrast levels can be applied until the normal and the abnormal parts can be observed ${ }^{[4]}$. Therefore, the role of contrast agents in MRI imaging is very important. Depending on the texture of the examining area that the appropriate scan sequence is selected ${ }^{[4]}$. For $\mathrm{T}_{1}$ weighed imaging, gadolinium based contrast agent (GBCA) is used very often. GCBA is a complex of lanthanide metal ion gadolinium $\left(\mathrm{Gd}^{3+}\right.$.) The most famous ligand for GBCA is the macrocyclic DOTA ${ }^{[5]}$ (figure 1.) The function GBCA is to interact with the water molecules in 
the examining area to reduce their protons' $\mathrm{T}_{1}$ time constants. Those time constants reflect the different relaxation of the protons in different environments and they are assigned with different color scales. Combining the location and the color scales, the $\mathrm{MRI} \mathrm{T}_{1}$ weighed image is formed ${ }^{[6]}$ [7]

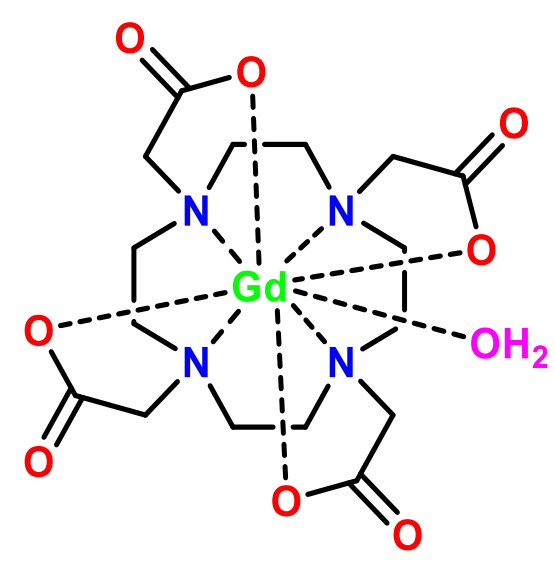

Figure 1: [GdDOTA]- interacts with a water molecule
The GBCA complex itself is safe for the human body. However, if decomplexation happens, the free metal ion $\mathrm{Gd}^{3+}$, whose radius is $108 \mathrm{pm}$, can displace the metal ion $\mathrm{Ca}^{2+}$, whose radius is $114 \mathrm{pm} . \mathrm{Ca}^{2+}$ participates in many biochemical processes of the cells in the human body. $\mathrm{Gd}^{3+}$ can act as a competitive inhibitor of $\mathrm{Ca}^{2+}$ and thus, disturb these processes [8]. That is why there is a growing concern about increasing the stability and thus, the safety of GBCA. In order to make $\mathrm{Gd}^{3+}$ favor staying in the complex, modification on the ligand

structure is necessary. This research focuses on modifying the macrocyclic (or the tetraaza ring) component of DOTA ligand.

\section{Mono-substitution results stimulated the study of di-substitution}

In the past studies, adding a nitro benzyl group on the tetraaza ring of DOTA affects the ability to form complex with $\mathrm{Gd}^{3+}$ of this new ligand (NB-DOTA.) [9] [10] Specifically, when NB-DOTA interact with $\mathrm{Gd}^{3+}$, a fixed ratio of two distinct complexes are formed ${ }^{[10]}$. These complexes are regioisomer of each other (figure 2.) Depending on the direction when $\mathrm{Gd}^{3+}$ approaches the ligand that corner or side regioisomers will form ${ }^{[10]}$. These regioisomers have different geometry, stability and energy, and thus, they have different contrast efficiency as showed in table $1^{[11]}$. The most important difference to notice between the two regioisomers is the water residence time $\left(\tau_{\mathrm{M}}\right)$ which is inversely proportional to the water exchange rate since this parameter reflects the interaction between the GBCA and the water molecules. These regioisomers can only be separated by HPLC (figure 3.) ${ }^{[10]}$ These fascinating results stimulated the further study on the effect of substitution on DOTA's tetraaza ring. Therefore, di-substitution became the subject in this study. 


\begin{tabular}{|lll|}
\hline & Corner & Side \\
$r_{\mathrm{GdH}} / \AA$ & 3.005 & 3.055 \\
$\tau_{\mathrm{M}}^{298 / \mathrm{ns}}$ & 188 & 12.4 \\
$\tau_{\mathrm{R}}^{298} / \mathrm{ps}$ & 90 & 120 \\
$\Delta H_{\mathrm{R}} / \mathrm{kJ} \mathrm{mol}^{-1}$ & 17 & 16 \\
$\Delta^{2} / 10^{19} \mathrm{~s}^{-2}$ & 0.86 & 1.2 \\
$\tau_{\mathrm{v}}^{298 / \mathrm{ps}}$ & 19.7 & 18 \\
$\Delta H_{\mathrm{V}} / \mathrm{kJ} \mathrm{mol}^{-1}$ & 1.0 & 1.0 \\
\hline
\end{tabular}

Table 1: Fitting Parameters for the NMRD Profiles of the Corner and Side Isomers of GdNB-DOTA in Aqueous Solution[11]
If two benzyl substituents are placed on the tetraaza ring of DOTA, two trends are expected. First, in order to maintain the stability of the ring, the conformation having the least steric hindrance will be favored. Secondly, the presence of the two bulky benzyl groups reduces the macrocyclic ring's mobility of the complex and thus, prevents the conversion between the isomer forms due to ring flipping. If these two trends are observed, they can support the hypothesis that di-substitution can control what type of regioisomers will be formed and thus, no additional steps to separate the side and corner regioisomers are needed since only one type will be formed. The three patterns will be studied and their expected dominating regioisomers are summarized in figure 4.
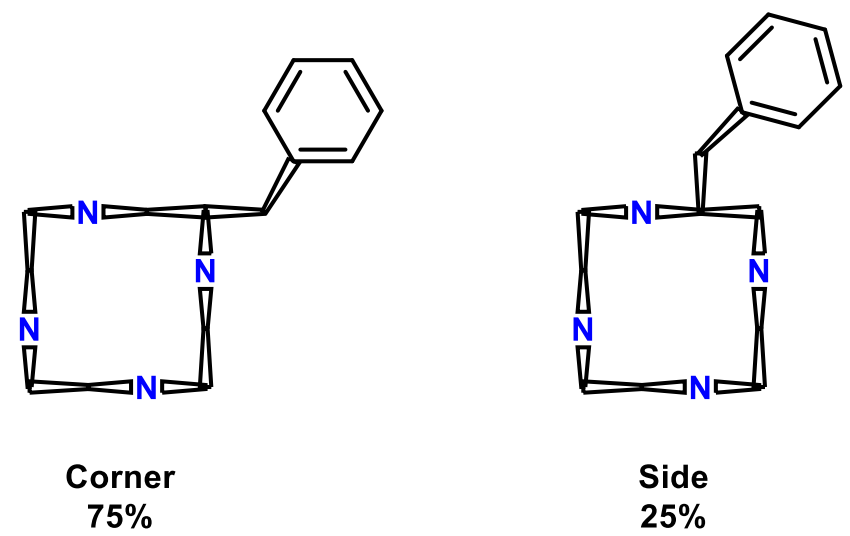

Side

$25 \%$

Figure 2: The tetraaza ring structure of the two regioisomers created by NB-DOTA ligand

Figure 3: The HPLC Chromatogram of the separation of Corner and Side ${ }^{[10]}$

\section{Corner} $(75 \%)$ 
2,8-S,S- disubstitution

Exclusively Corner?
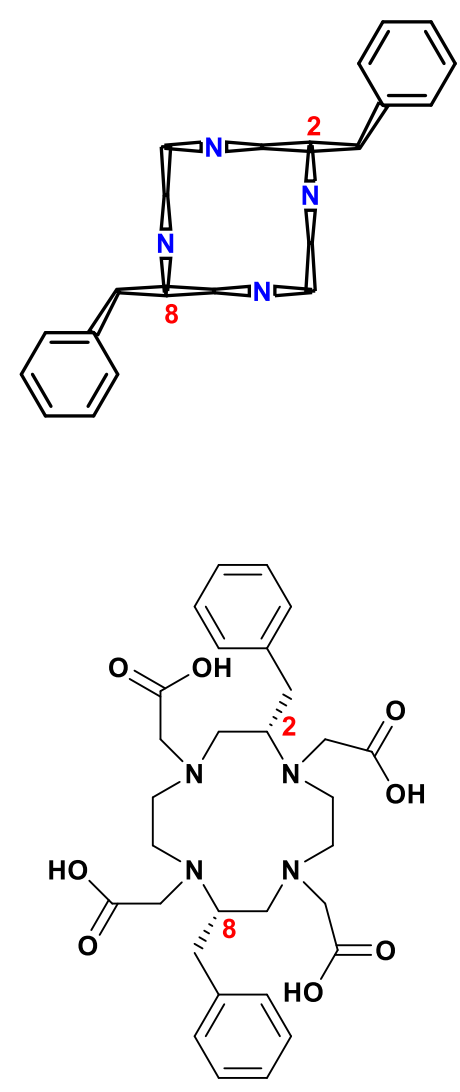

2,8-S,S- dibenzyl DOTA
2,9-S,S- diubstitution

Corner and Side
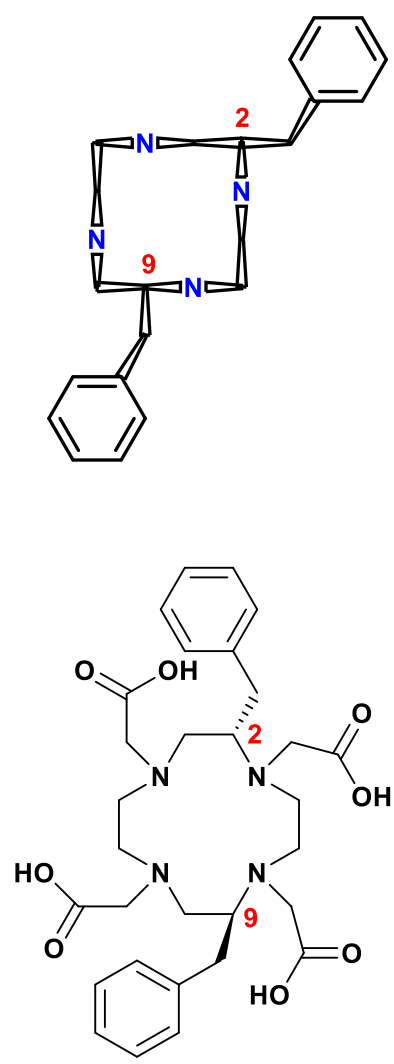

2,9-S,S- dibenzyl DOTA
2,5-S,S- disubstitution

Exclusively Corner?
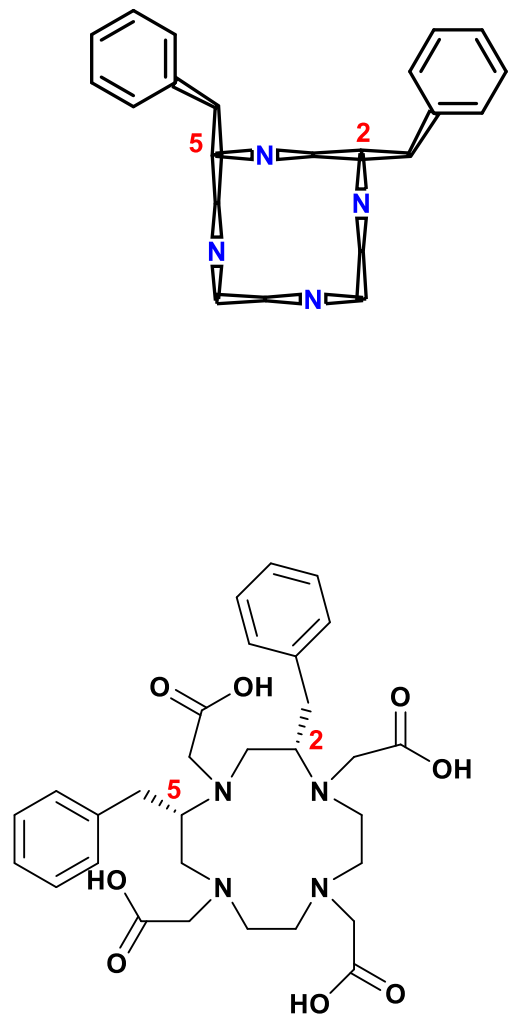

2,8-S,S-dibenzyl DOTA

Figure 4: The summary of the three di-substitution patterns on DOTA's tetraaza ring and their expected complex's regioisomer

For the pattern 2,8-S,S and 2,5-S,S, the benzyl groups are on the same plane so the only way to minimize steric hindrance is to favor conformation having them in the equatorial positions. Once the complex is formed, corner regioisomer is more favorable since it has less steric hindrance. For the case of pattern 2,9-S,S, both corner and side regioisomers are expected but the specific ratio cannot be predicted since the two benzyl groups are located on the different plane of the ring. This allows the macrocyclic ring of its complex to have more mobility comparing to the other patterns.

\section{Developing synthesis strategy to control the desired di-substitution patterns}

The synthesis of these di-substituted DOTA includes four main stages: dibenzyl polypeptide chain, dibenzyl tetra amine chain, dibenzyl tetraaza cyclododecane, and dibenzyl DOTA. From the pure simple amino acids and amine, the dibenzyl peptide chain is built by using the peptide synthesis 
techniques. Building the peptide chain is an important stage because it determines the position of the benzyl substituents on the tetraaza ring in the future. Cyclization in the third stage is necessary since the substituents need to be located on the tetraaza ring before the pendant arms are added. However, once the tetraaza ring is closed, the substituents will more likely to be attacked the lone pairs of the nitrogen atoms. Those nitrogen spots must be saved for the pendant arms to create the desired DOTA derivative forms. Therefore, the position of the benzyl substituents must be defined on the precursors of the tetraaza ring. The retro synthesis plan for the three patterns are showed in the figure 5 below:
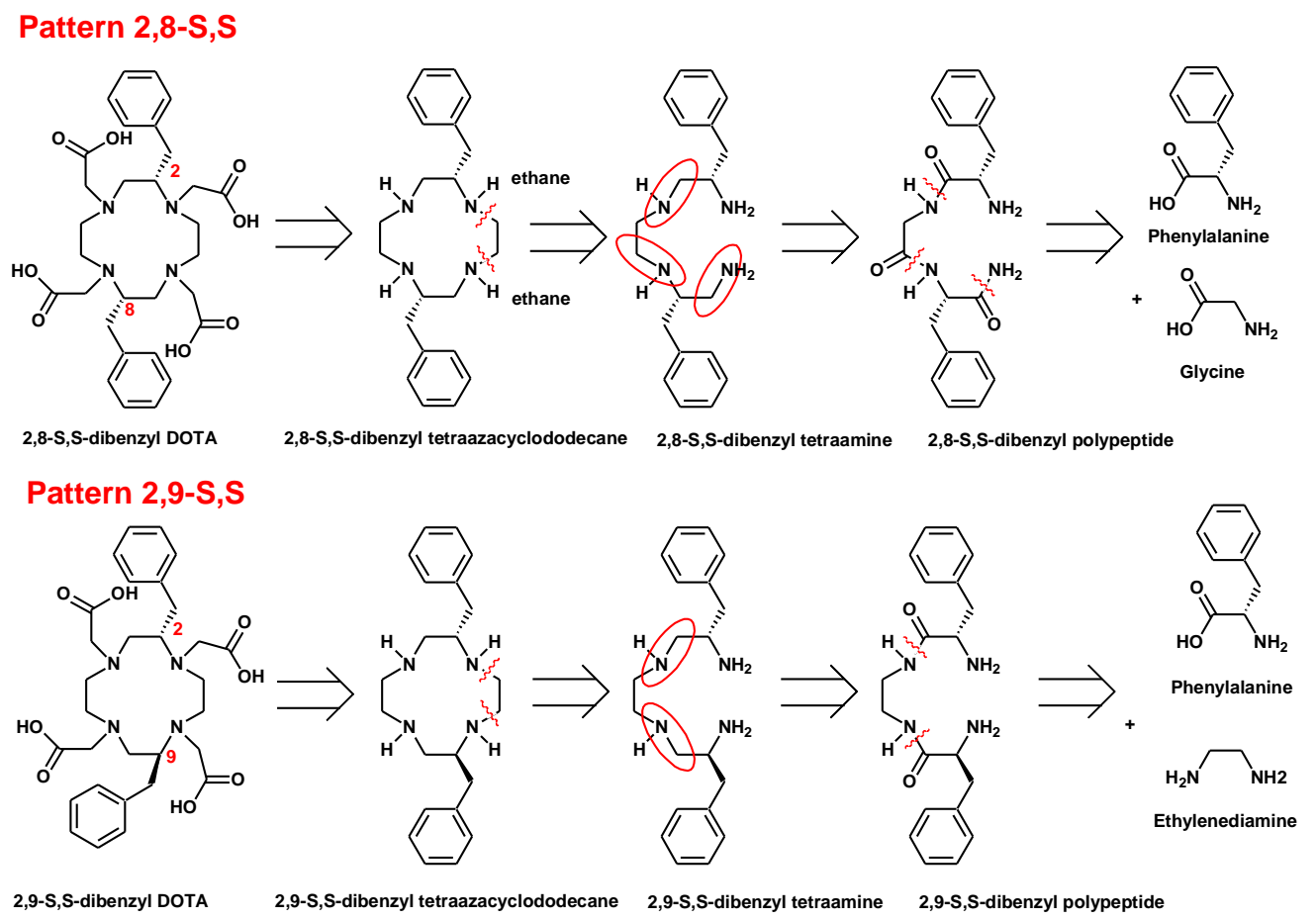

\section{Pattern 2,5-S,S}

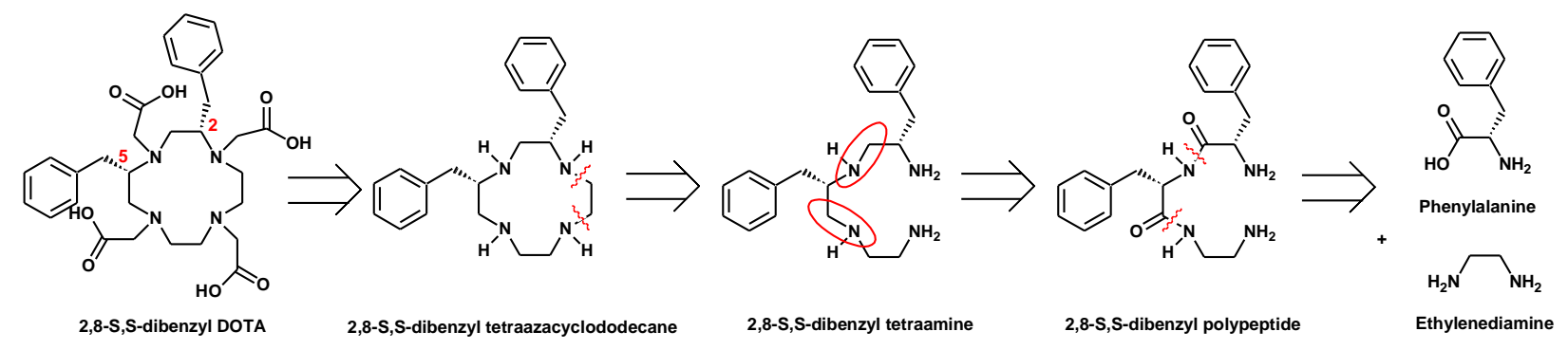


Cyclization procedure is based on the method developed by Reed and Weisman ${ }^{[12]}$ to synthesize cyclen. Figure 6 below summarizes the cyclization process of the pattern 2,9-S,S with R is the abbreviation of the benzyl group
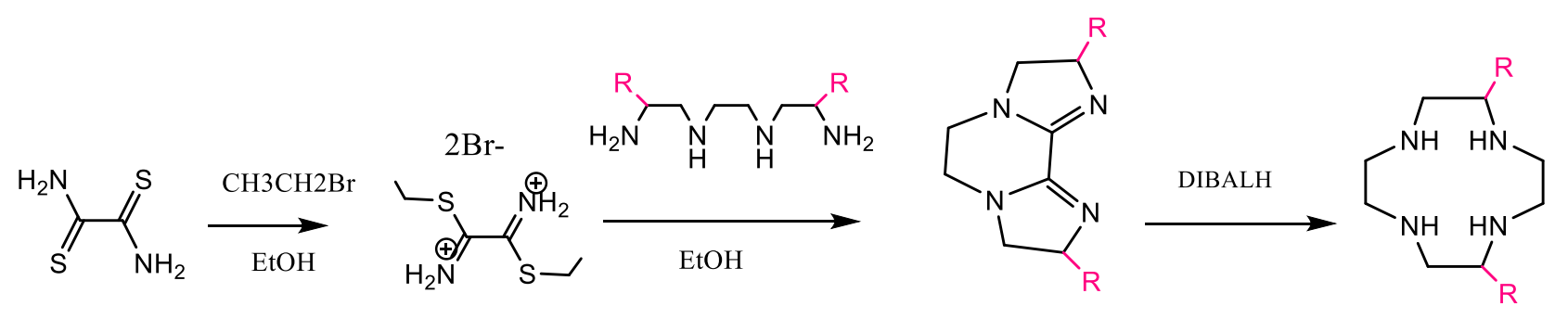

Figure 6: The summary of the cyclization process for the pattern 2,9-S,S

\section{RESULTS AND DISCUSSION}

\section{The progress of pattern 2,8-S,S}

The synthesis progress of pattern 2,8-S,S is summarized in figure 7 below:

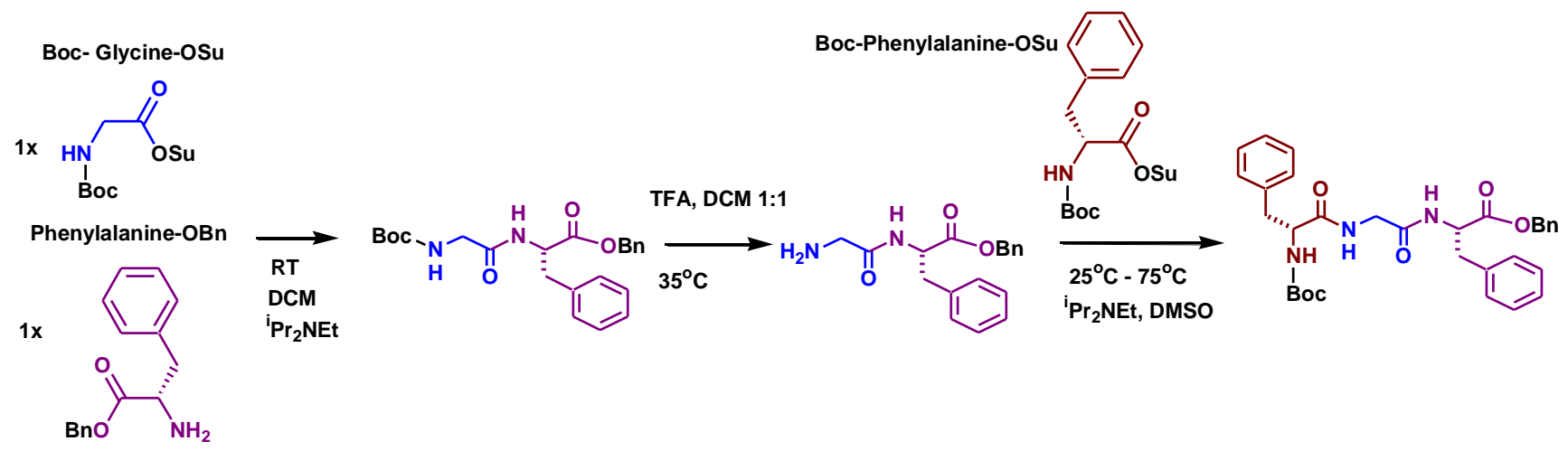

Figure 7 The summary synthesis progress of the pattern 2,8-S,S<smiles>NC(=O)[C@H](Cc1ccccc1)NC(=O)CNC(=O)[C@H](N)Cc1ccccc1</smiles>

Figure 8: 2,8-S,S-dibenzyl polypeptide
The polypeptide chain of this pattern (figure 8) could not be built from the $\mathrm{N}$ terminal in the first attempt. The issue with solubility already happened after the first peptide bond was built but it was neglected since the intermediate solid product could not dissolve in $\mathrm{CDCl}_{3}, \mathrm{MeOH}, \mathrm{H}_{2} \mathrm{O}$ or $\mathrm{MeCN}$ with some drops of ${ }^{i} \operatorname{Pr}_{2} \mathrm{Net}$ but DMSO. Using too much DMSO solvent $(150 \mathrm{~mL})$ during the process of building the second peptide bond was a big mistake since it required a lot of heat to vaporize DMSO. Increasing the temperature of the water bath too high lead to the unwanted removal of the 
Boc protection group on the $\mathrm{N}$ terminal of Phenylalanine. The product could not be dissolved in the available organic solvent, therefore, no ${ }^{1} \mathrm{H}-\mathrm{NMR}$ nor mass spectrometry analysis could be done. This solid formed complex with $\mathrm{Cu}^{2+}$ and dissolved in the mixture of $\mathrm{H}_{2} \mathrm{O}$ and $\mathrm{MeOH}$. However, the result from the mass spectrometry analysis could not confirm the presence of desired product. The fact that this solid could form complex with $\mathrm{Cu}^{2+}$ confirmed that there were peptide bond formed (Amide can form complex with $\mathrm{Cu}^{2+}$ ) but specifically whether they were the desired ones or not could not be concluded. The next step for this pattern will be (a) redo the $\mathrm{N}$ terminal using a smaller amount of DMSO or develop a mixture of the different solvents that the intermediate product can dissolve and (b) trying to build the peptide bonds from the $\mathrm{C}$ terminal: letting Boc-Phe-OSu reacts with ammonium then remove the Boc group and build the next bond.

\section{The progress of pattern 2,9-S,S}

The synthesis progress of pattern 2,9-S,S is summarized in figure 9 below:
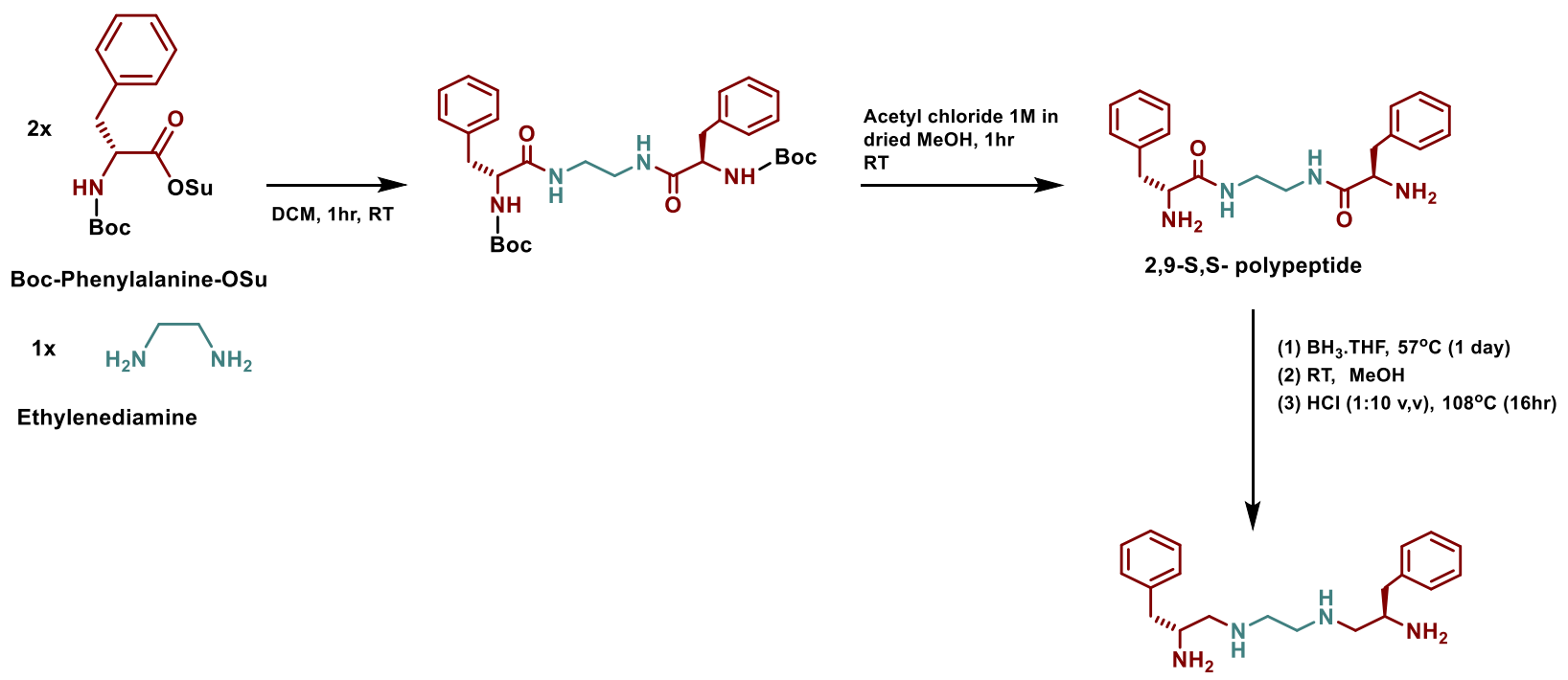

2,9-S,S- tetraamine

Figure 9: The summary synthesis progress of the pattern 2,9-S,S

This pattern is easier to synthesize than the other ones. All the desired peptide bonds were built in one step. After removing the Boc protection group, the polypeptide was successfully reduced to the desired tetraamine chain. The tetraamine chain is not ready for the cyclization process yet since is still in the aqueous layer. The ${ }^{1} \mathrm{H}-\mathrm{NMR}$ spectrum of the organic layer did not have the aromatic signal from the benzyl substituents. In addition, the signals from the solvent were much stronger 
than the examining compound's. The protons from the linear chain and the benzyl substituents of 2,9-S,S-dibenzyl tetraamine showed up in the ${ }^{1} \mathrm{H}-\mathrm{NMR}$ spectrum of the aqueous layer. However, this spectrum also contains strong signal from the solvent $\mathrm{MeOH}$. Therefore, the next step will be developing a HPLC method to purify $2,9-\mathrm{S}, \mathrm{S}$ dibenzyl tetraamine chain. The ${ }^{1} \mathrm{H}-\mathrm{NMR}$ spectrum and the mass spectrum of this tetraamine chain are showed in figure 10. The molecular weight of the target molecule is $326.25 \mathrm{amu}$. The results from running the mass spec in the positive mode $\left(\mathrm{M}+\mathrm{H}^{+}\right)$has a significant high peak of 327.25 and thus, confirmed the presence of 2,9-S,S-dibenzyl tetraamine chain in the aqueous layer.
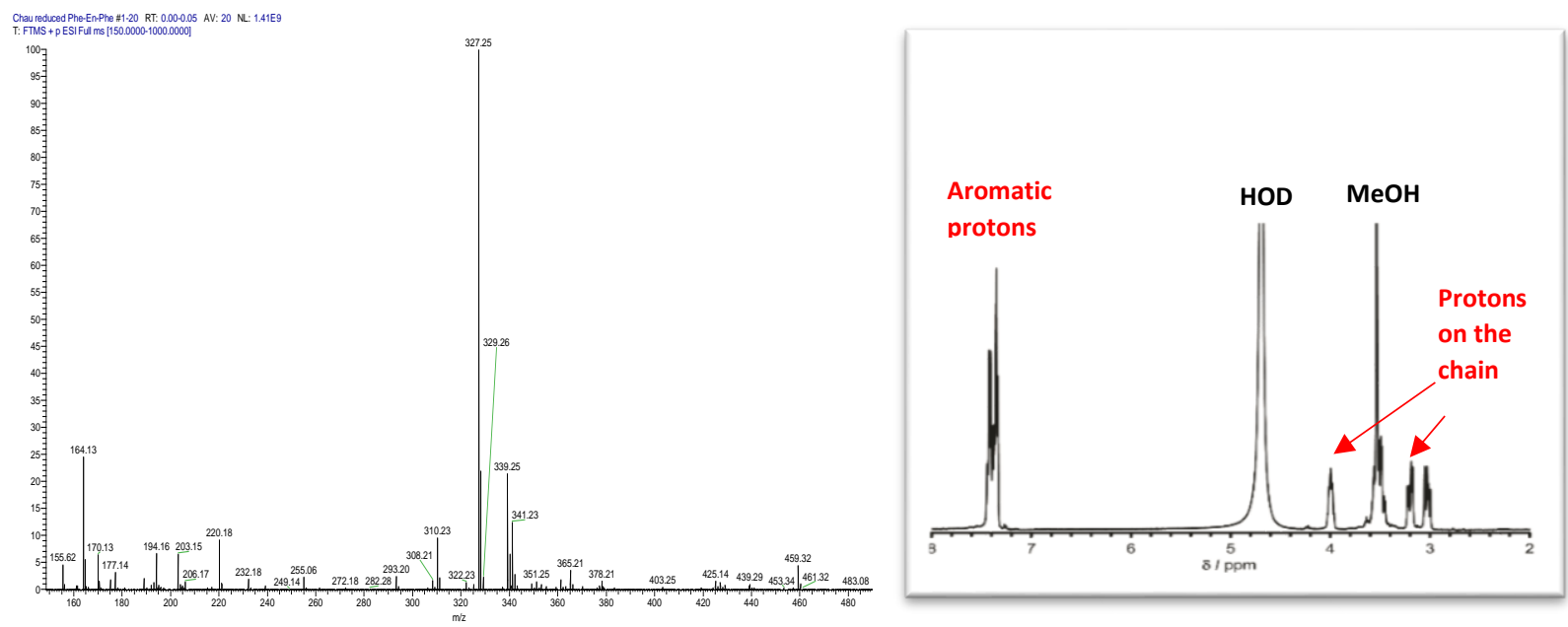

Figure 10: The mass spectrum (left) and the ${ }^{I} H$-NMR spectrum (right) of 2,9-S,S dibenzyl tetraamine

\section{The progress of pattern $2,5-\mathrm{S}, \mathrm{S}$}

The synthesis progress of pattern 2,5-S,S is summarized in figure $\mathbf{1 1}$ below:

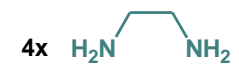

Ethylenediamine

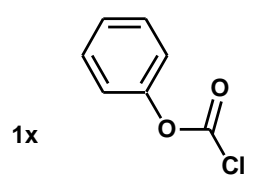

Benzyl chloroformate
DCM, $0^{\circ} \mathrm{C}, 1 \mathrm{hr}$

stir RT (16hr)

$\mathrm{Cu}(\mathrm{OH})_{2} \mathrm{CuCO}_{3}(1 \mathrm{x}), \mathrm{H}_{2} \mathrm{O}, \mathrm{pH}=12$

(1hr)
Boc-Phenylalanine-OSu

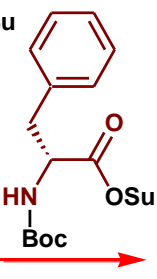<smiles>CC(C)(C)OC(=O)N[C@H](Cc1ccccc1)C(=O)NCCNC(=O)O</smiles>

Figure 11: The synthesis progress of pattern 2,5-S,S 


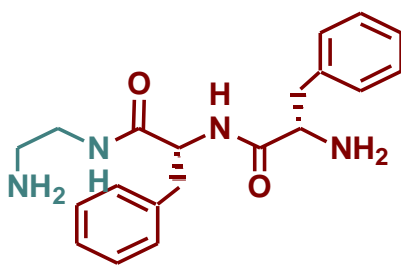

Figure 12: 2,5-S,S-dibenzyl polypeptide

This pattern is still at the stage of making the polypeptide chain which is showed in the figure 12. The strategy is to build from the $\mathrm{N}$ terminal: one side of Ethylene diamine is covered with the $\mathrm{Cbz}$ protection and the other is left active to build the first peptide bond with Boc-Phenylalanine-OSu. However, after putting the $\mathrm{Cbz}$ in, the product needed to be separated from the matrix. In the first trial, the last NMR spectra did not confirm the presence of Ethylene diamine having one protected side. There might be not enough Ethylene diamine. In the contrary, the dry flash column chromatography in the second trial was necessary because there was still some unprotected Ethylene diamine (its present was confirmed when comparing TLC of fraction 2 with Ethylene diamine in $\mathrm{MeOH}$.) The three fractions obtained from the column are still being analyzed. Specifically, when performing the TLC comparing with the solvent $\mathrm{MeOH}$ and the mixture of $\mathrm{MeOH}$ and $\mathrm{Et}_{2} \mathrm{O}$, fraction 2 seems to contain the desired product because it had different retention factor than the solvent's. Fraction 1 had the retention factor no different than the solvent. By that time fraction 3 was not dried yet to run TLC. Therefore, fraction 2 must be analyzed first. A large amount of $\mathrm{MeOH}$ and $\mathrm{Et}_{2} \mathrm{O}$ was added in fraction 2 in attempt to separate the desired product through crystallization. The NMR spectra of crystal from fraction 2 and the original fraction 3 in DMSO have not been analyzed yet.

\section{EXPERIMENTAL PROCEDURE}

The four starting materials for the peptide synthesis in this project are Boc-Glycine-OSu (BocGly-OSu), L Phenylalanine-OBn (Phe-OBn), Boc-Phenylalanine-OSu (Boc-Phe-OSu), and Ethylene diamine. Another goal must be achieved is to see if it is possible to make the desired polypeptide chains with a minimum number of the pure, prepared and simple amino acids. All amino acids used in this experiment were purchased from TCI America. Ethylene diamine and the other chemicals were purchased from Sigma-Aldrich. The mass spectrometry analysis were performed by using the ThermoElectron LTQ-Orbitrap Discovery high resolution mass spectrometer with an Accela HPLC system. The H-NMR spectra were collected by using the Bruker $400 \mathrm{MHz}$ Avance II and spectrometer with the default probe is $5 \mathrm{~mm}$ BBFO. The use of the corrosive Ethylene diamine, air sensitive and toxic chemicals TFA, $\mathrm{BH}_{3}$.THF, Benzyl 
chloroformate and the operation of the Schlenk line followed the safety instruction of the Chemistry Department of the Portland State University.

Pattern 2,8-S,S

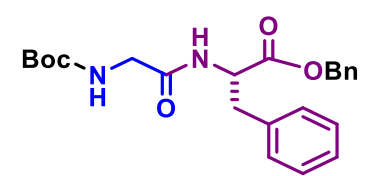

Figure 13: 2,8-S, S pattern first peptide bond with Boc and $\mathrm{OBn}$ protection

13) was built.

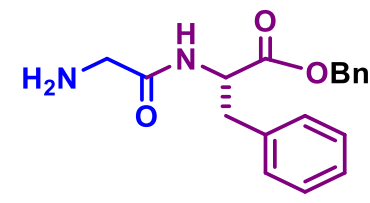

Figure 14: 2,8-S,S pattern first peptide bond with OBn protection
Phe-OBn (10.3mmol) was mixed with Boc-Gly-OSu (10.5mmol) in the solvent containing DCM (100mL) and ${ }^{i} \operatorname{Pr}_{2} \operatorname{Net}(10.3 \mathrm{mmol}$.) The mixture was stirred at the room temperature for 2 hours before getting a base wash with supersaturated $\mathrm{Na}_{2} \mathrm{CO}_{3}$ and then extracted with DCM. After drying off the solvent DCM, the intermediate product (5.44g) was collected and an NMR analysis in $\mathrm{CDCl}_{3}$ was performed. The first peptide bond (figure

This intermediate product was mixed with a solvent containing DCM $(25 \mathrm{~mL})$ and TFA $(25 \mathrm{~mL})$ in air free condition and stirred for 1 hour at $35^{\circ} \mathrm{C}$. Another round with base wash and extraction with DCM was performed. After drying, $6.04 \mathrm{~g}$ of solid was collected. This solid could not dissolve in $\mathrm{CDCl}_{3}, \mathrm{MeOH}, \mathrm{H}_{2} \mathrm{O}$ or $\mathrm{MeCN}$ with some drops of ${ }^{\mathrm{i}} \mathrm{Pr}_{2} \mathrm{Net}$ but DMSO. No NMR nor mass spectrometry analysis was performed but the expected structure is showed in figure 14.

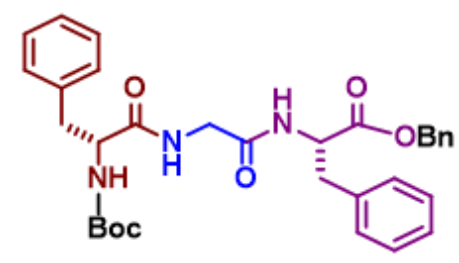

Figure 15: 2,8-S,S pattern first and second peptide bonds with $B o c$ and OBn protection

The solid was dissolved in the solvent containing DMSO (150mL) and ${ }^{\mathrm{i}} \mathrm{Pr}_{2} \mathrm{Net}(10.3 \mathrm{mmol})$, mixed with Boc-Phe-OSu (10.3 mmol), stirred at room temperature for one day. DMSO was removed by rotovaping with the temperature increasing gradually from $25^{\circ} \mathrm{C}$ to $75{ }^{\circ} \mathrm{C}$. The white oily product could not dissolve in any available organic solvents nor the mixture of them. No NMR analysis was performed but the expected structure is showed in figure 15. This intermediate formed a complex with $\mathrm{Cu}^{2+}$ and this complex dissolved in $\mathrm{H}_{2} \mathrm{O}$ and $\mathrm{MeOH}$. Mass spectrometry analysis on this complex was performed but there was no sign of the expected molecule appeared on the mass spectrum. 
Pattern 2,9-S,S

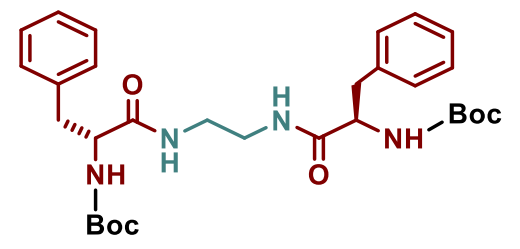

Figure 16: 2,9-S,S dibenzyl poly peptide with Boc protection groups

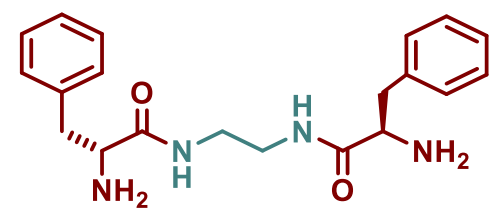

Figure 17: 2,9-S,S dibenzyl polypeptide

Ethylene diamine $(3.30 \mathrm{mmol})$ was mixed with Boc-Phe-OSu $(6.92 \mathrm{mmol})$ in DCM $(100 \mathrm{~mL})$ and stirred at room temperature for 1 hour before getting a base wash with $\mathrm{Na}_{2} \mathrm{CO}_{3}$ and extracted with DCM to collect the organic layer. This layer was kept at $0^{\circ} \mathrm{C}$ for 5 days before decanting the solvent. ${ }^{1} \mathrm{H}-\mathrm{NMR}$ in MeOD was performed. At this stage, the two desired peptide bonds were formed (figure 16.)

To remove the Boc group, the intermediate product was mixed with the solution of $1 \mathrm{M}$ acetyl chloride in dried $\mathrm{MeOH}$ and stirred in air free condition at room temperature for 1 hour. After adding $\mathrm{MeOH}$ $(50 \mathrm{~mL})$ and $\mathrm{Et}_{2} \mathrm{O}(100 \mathrm{~mL})$, the sample was stored at $0^{\circ} \mathrm{C}$ for 10 days. After decanting the solvent, $0.7537 \mathrm{~g}$ of light green yellow crystal was collected. ${ }^{1} \mathrm{H}-\mathrm{NMR}$ in $\mathrm{D}_{2} \mathrm{O}$ was performed on the sample of this crystal. At this point, the peptide chain (figure 17) was completed.

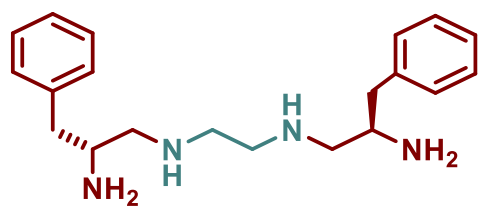

Figure 18: 2,9-S,S dibenzyl tetraamine

This crystal $(0.4251 \mathrm{~g})$ was mixed with $\mathrm{BH}_{3}$.THF $(30 \mathrm{~mL})$ and heated at $57^{\circ} \mathrm{C}$ for 1 day in inert atmospheric condition. When the mixture cooled down to room temperature, $\mathrm{MeOH}(50 \mathrm{~mL})$ was added by portion before stirring for 1 hour. Small portion of $\mathrm{MeOH}$ was added until no bubble of $\mathrm{H}_{2}$ was observed. This indicated that the Boron complex was deactivated. The solvent was removed. Four rounds of washing the solid with $\mathrm{MeOH}(100 \mathrm{~mL}$ each time) and removing the solvent were done and the product was an orange-brown oil with very uncomfortable fishy smell was collected. This oil was mixed with $\mathrm{HCl}$ solution $(30 \mathrm{~mL}, 1: 10 \mathrm{v}, \mathrm{v})$ and heated at $108^{\circ} \mathrm{C}$ for 16 hours. $\mathrm{KOH}$ tablets were added by portion until the $\mathrm{pH}$ reached 14. After the extraction with DCM, both aqueous and organic layers were saved to analyze. The solvent was dried off from the organic layer and the ${ }^{1} \mathrm{H}-\mathrm{NMR}$ spectrum in $\mathrm{CDCl}_{3}$ of this intermediate product was collected. Pure water was added in the aqueous layer until the final volume equal to three times of the initial volume. This mixture was kept at $-40^{\circ} \mathrm{C}$ for two days before removing frozen solvent by freeze drying. The ${ }^{1} \mathrm{H}-\mathrm{NMR}$ spectrum in $\mathrm{D}_{2} \mathrm{O}$ and the 
mass spectra in $\mathrm{H}_{2} \mathrm{O} / \mathrm{MeOH}$ of this newly collected solid were obtained. The target molecules (figure 18) was found in the aqueous layer.

\section{Pattern 2,5-S,S}

Two trials with different starting amount of Ethylene diamine and Benzyl chloroformate were made as showed in table 2 below:

\begin{tabular}{|c|c|c|c|}
\hline Trial & Ethylene diamine (mmol) & Benzyl chloroformate (mmol) & Ratio \\
\hline 1 & 28 & 14 & $2: 1$ \\
2 & 58 & 14.5 & $4: 1$ \\
\hline
\end{tabular}

Table 2: The summary amount of the starting materials in two trials

In both trials, the first goal was to add a Cbz protection group on one end of Ethylene diamine (figure 19)

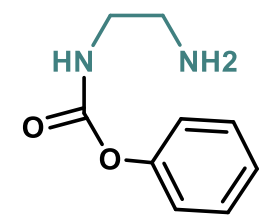

Figure 19: Ethylene diamine with $\mathrm{Cbz}$ protection to build the first peptide bond of the 2,5-S,S pattern
In trial 1, an air free condition was obtained by using the pressure equalizing funnel drop. At $0^{\circ} \mathrm{C}$, Ethylene diamine was added in DCM (100mL), then Benzyl chloroformate was added and the mixture was stirred for 1 hour before the addition of $\mathrm{H}_{2} \mathrm{O}(15 \mathrm{~mL})$. After extracting and removing the solvent DCM from the organic layer, the product was dissolved in $\mathrm{CDCl}_{3}$ to run ${ }^{1} \mathrm{H}-\mathrm{NMR}$ but it was not the desired molecule. In trial 2, after Ethylene diamine and Benzyl chloroformate got mixing in the same condition in the trial 1 , the mixture was stirred overnight. $\mathrm{Cu}(\mathrm{OH})_{2} \mathrm{CuCO}_{3}(14.5 \mathrm{mmol})$ in $\mathrm{H}_{2} \mathrm{O}(20 \mathrm{~mL})$ was slowly added and stirred. When the $\mathrm{pH}$ was 12 , the organic layer was extracted with DCM and dried. ${ }^{1} \mathrm{H}-\mathrm{NMR}$ analysis in MeOD was performed. TLC comparing with Ethylene diamine was performed. Dry flash column chromatography was performed on the sample with the first wash was $\mathrm{Et}_{2} \mathrm{O}$ and three fractions in $\mathrm{MeOH}$. When all fractions dried, TLC tests comparing with $\mathrm{MeOH}$, mixture of $\mathrm{MeOH}(35 \%)$ and $\mathrm{Et}_{2} \mathrm{O}(65 \%)$, and Ethylene diamine were performed to find the fraction containing the most amount of the product. A significant larger amount of the solvent containing $\mathrm{MeOH}$ and $\mathrm{Et}_{2} \mathrm{O}$ (ratio 1:2) was added in the fraction 2. After one day, the solvent was decanted to collect the crystalized solid. ${ }^{1} \mathrm{H}-\mathrm{NMR}$ in DMSO of the crystalized fraction 2 and the fraction 3 were performed. 


\section{ACKNOWLEDGEMENT}

The author would like to thank Dr. Mark Woods and the BUILD EXITO Program for giving her such a precious opportunity to participate in this wonderful research. The author also appreciates the supports from all of the graduate students in Dr. Woods' lab. 


\section{REFERENCES}

[1] Brenner, D.J; Hall, E.J. New England Journal of Medicine 2007, 357, 2277

[2] de Gonzalez, A. B; Darby, S. The Lancet 2004, 363,345.

[3] Rothkamm, K.; Barloop, S.; Skerhdar, J.; Fernie, P; Goh, V. Radiology 2007, 242,244.

[4] R. Bitar et al; MR Pulse Sequences: What Every Radiologist Wants to Know but Is Afraid to Ask. Radiographics 2006.

[5] Loncin, M. F; Desreux, J.F and Merciny, E. Inorganic Chemistry 198625 (15), 2646-2648

[6] E.J. Blink; MRI principles. 2004

[7] C. Westbrook et al; MRI in Practice. 2011

[8] Rogosnitzky, M. \& Branch, S. Gadolinium-based contrast agent toxicity: a review of known and proposed mechanisms. Biometals 29, 2016, 365-376

[9] Woods, M.; Kovacs, Z.; Kiraly, R.; Brücher, E.; Zhang, S.; \& Sherry, A. Solution dynamics and stability of lanthanide(III) (S)-2-(p-nitrobenzyl)DOTA complexes. 2004 Inorganic Chemistry, 43(9), 2845-51.

[10] Payne, K. \& Woods, M. Isomerism in benzyl-DOTA derived bifunctional chelators: Implications for molecular imaging. Bioconjugate Chemistry, 2015, 26(2), 338-44.

[11] Rust, L; Payne, K; Carniato, F; Botta, M; and Woods, M. Differences in the Relaxometric Properties of Regioisomeric Benzyl-DOTA Bifunctional Chelators: Implications for Molecular Imaging. Bioconjugate Chemistry 201930 (5), 1530-1538

[12] Weisman, G. R.; Reed, D. P. J. Org. Chem. 1996, 61, 5186; (b) Correction: J. Org. Chem. 1997, 62, 4548. 